\title{
The McCollough effect across the menstrual cycle
}

\author{
MOIRA S. MAGUIRE \\ University of Luton, Luton, England \\ and \\ WILLIAM BYTH \\ The Queen's University of Belfast, Belfast, Northern Ireland
}

\begin{abstract}
The McCollough effect (ME) has been shown to be sensitive to cholinergic agents, being strengthened by hyoscine (antagonist) and weakened by physostigmine (agonist), and possibly to more generalized changes in CNS arousal. We therefore expected the ME to be sensitive to hormonal changes during the menstrual cycle, being strongest in the postovulatory phases when arousal is low. In two experiments we found a highly significant effect of menstrual phase for the normally cycling women, but not for oral contraceptive users: ME strength gradually increased across the cycle, reaching a premenstrual peak. These findings may be explained in terms of hormonally mediated changes in arousal across the menstrual cycle.
\end{abstract}

The McCollough effect (ME) is generated by the nonrandom repeated pairing of a color and orthogonally oriented gratings. For example, when red/black horizontal gratings are alternated with green/black vertical gratings during adaptation, the subsequent viewing of an achromatic test stimulus containing both horizontal and vertical white/black gratings results in the perception of a green aftereffect against the horizontal gratings and magenta aftereffect against the vertical. The aftereffect is part of a larger class of pattern-contingent color aftereffects (CAEs) and has been extensively reviewed (e.g., Dodwell \& Humphrey, 1990; J. P. Harris, 1987; Skowbo, Timney, Gentry, \& Morant, 1975).

When Celeste McCollough first reported the effect in 1965 , she assumed it to be the result of neural adaptation. However, many features of the ME, particularly its persistence, are clearly incompatible with models based on fatigue (see, e.g., Byth, Logue, Bell, Best, \& King, 1992; Dodwell \& Humphrey, 1990). For these reasons a number of authors have suggested that the ME must be the product of some sort of associative learning process. Murch's (1976) suggestion that the ME is a classically conditioned response has been extensively debated (see, e.g., Allan \& Siegel, 1986; C. S.Harris, 1980; McCarter \& Silver, 1977; Murch, 1977; Skowbo, 1984, 1986) without any general agreement that classical conditioning provides an adequate explanation of all features of the ME.

An alternative approach, following Andrews (1964) and Anstis (1975), is to assign a functional role to the ME as an error correcting device (ECD). Both Shute (1979) and

The experiments described were conducted in the Psychology Department of The Queen's University of Belfast. We wish to thank three anonymous referees for their helpful suggestions regarding a previous draft of this paper. Correspondence regarding this paper should be sent to M. Maguire, Department of Psychology, University of Luton, Luton LUI 3JU, England (e-mail: moira.maguire@luton.ac.uk).
Dodwell and Humphrey (1990) consider the ME to reflect the activity of an adaptive mechanism for eliminating spurious associations, such as that between color and orientation.

Two characteristics of MEs make ECD explanations particularly attractive. The first is that the effects do not show appreciable decay until after the first test following adaptation has been made, and this may be weeks later (see, e.g., Jones \& Holding, 1975). This offers little support for either neural adaptation or a decaying memory store but is compatible with an ECD or similar associative learning hypothesis. That is, very little decay occurs until the ECD is triggered to counteract a spurious association with color elicited by an achromatic pattern. Once the mechanism is triggered, the ME decays to extinction at a fairly predictable rate (see, e.g., Logue \& Byth, 1993; Mackay \& Mackay, 1974; White, 1977), depending on the strength at the initial test (e.g., Riggs, White, \& Eimas, 1974; Shute, 1979), except possibly when the test luminance is extremely low (Skowbo, Garrity, \& Michaud, 1985).

The second characteristic of contingent aftereffects, which supports an ECD hypothesis, is that they do not transfer interocularly at the first test when the nonadapted eye is occluded or exposed to homogenous achromatic illumination during adaptation (McCollough, 1965; Skowbo et al., 1975), but do transfer to the nonadapted eye once they have been elicited in the adapted eye (e.g., Byth et al., 1992; Kaufman, May, \& Kunen, 1981; Logue \& Byth, 1993; Shute, 1979). This suggests that the formation and storage of the spurious pattern-color association may occur at the monocular level, but that the ECD, once triggered, operates at both monocular and binocular levels.

White, Petry, Riggs, and Miller (1978) reported interocular transfer at the first test, but this seems to have depended on partial contingencies set up during adaptation when the nonadapted eye was exposed to colored fields identical or complementary to that illuminating the adapted eye. Other reports suggest that binocular interactions do 
occur during adaptation when both eyes are exposed to combinations of color and/or pattern (Shute, 1979; Vidyasagar, 1976; White et al., 1978). Mikaelian (1975) found interocular transfer of reversed or "second order" MEs, but only following binocular scanning of the test pattern which we might assume would trigger the ECD.

ECD models differ in background and emphasis. Dodwell and Humphrey (1990) explain the ME and related effects in the mathematical terms of the Lie transformation group model of neurophysiology. They consider such effects to be dependent on global pattern organization (see, e.g., Dodwell \& O'Shea, 1987), although Broerse and O'Shea (1995) have shown that CAEs may be explained by more local edge and spread-color components. Shute's (1979) model is physiological and is more directly related to our hypotheses: he considered the ME to be the product of a cholinergically driven learning-forgetting mechanism in the hippocampus. He suggested that the initial strength of the ME varied inversely with levels of cholinergic activity and supported this with a number of uncontrolled exploratory observations. We have verified this in a number of drug studies with normal male subjects: $\mathrm{ME}$ strength is depressed by cholinergic agonists (physostigmine) and elevated by antagonists (hyoscine) (Byth et al., 1992; McMahon, 1993). However, initial strength is also reduced by caffeine (Maguire \& Byth, 1995; Shute, 1979) and nicotine (Amure, 1978), which do not exert their actions primarily through the cholinergic system, although ACh may be involved.

The effect is also sensitive to extraversion, which, according to Eysenck (e.g., 1967), reflects differences in central arousal: Extroverts tend to be underaroused and seek stimulation, whereas introverts are overaroused and avoid stimulation. Logue and Byth (1993) found that male extroverts have stronger effects than introverts, and these effects decay more quickly. However, there is no evidence of extensive cholinergic involvement in personality, although there is some evidence that cholinergic activity may be correlated positively with arousal (see, e.g., Spehlmann \& Downes, 1974).

These findings suggest that the ME is sensitive not only to cholinergic activity, but to CNS activity or arousal in general (Byth \& Maguire, 1995). Since gonadal hormones are known to affect central activity and evidence suggests that CNS activity varies across the menstrual cycle (Asso, 1983; Richardson, 1992), we expected the ME to be sensitive to changes across the menstrual cycle.

The experiments described here were conducted to investigate the strength of MEs reported by women at each phase of their menstrual cycle. Well-established menstrual rhythms have been recorded in all sensory modalities (Gandleman, 1983; Parlee, 1983). It is likely that many of these are not the result of local hormonal action, but rather are the result of hormonally mediated changes in central activity (see, e.g., Doty, Huggins, Snyder, \& Lowry, 1981). Gonadal hormones are known to affect CNS arousal and activation (Dye, 1992): Estrogens have an activating effect, whereas progesterone has a deactivating effect. Es- trogens also tend to inhibit the synthesis of acetylcholine, thereby reducing cholinergic activity (Broverman et al., 1981). Therefore during the preovulatory phases of the menstrual cycle, as levels of estrogens rise, so too does central activation, while cholinergic activity declines. The release of progesterone after ovulation causes a fall in arousal, which is further decreased after the rapid decline of hormones in the premenstrual phase.

Five main phases of the menstrual cycle have been identified (see, e.g., Asso, 1983), as follows: (1) Menstrual phase (Days 1-5); follicle stimulating hormone (FSH) is released. (2) Follicular phase (Days 6-12); FSH causes a sharp rise in estrogen levels; lutenising hormone (LH) is released. (3) Ovulatory phase (Days 13-15); high levels of LH cause the release of an ovum. (4) Luteal phase (Days 16-23); the empty follicle becomes a corpus luteum and secretes progesterone. (5) Premenstrual phase (Days 23-28); a sudden drop in levels of estrogen and progesterone leads to the endometrial shedding in Menstrual Phase 1.

The following experinents were designed to test the hypothesis that ME strength would vary systematically through the natural menstrual cycle. Since, as we have shown (Byth et al., 1992), the ME initial strength is inversely related to levels of cholinergic activity, we might expect the ME to be strongest in the first part of the cycle when rising estrogen levels reduce cholinergic activity. If, however, the ME has an inverse relationship with arousal in general, initial strength might be greatest in the postovulatory phases.

\section{GENERAL METHOD}

The method employed here is one we have used in previous studies of the ME, testing hypotheses derived from Shute (Byth et al., 1992; Logue \& Byth, 1993), in which we have presented data confirming the validity, reliability, and sensitivity of the method. Shute $(1977,1979)$ considered his match-interference method to be an analogue of an ECD whereby the spurious color association is canceled by the operation of opponent color channels. We continue to use the method, because, like saturation rating scales and unlike nulling methods, it does not require the introduction of a cancellation color to the achromatic test pattern which may affect the strength of the $\mathrm{CAE}$ phantom color.

In the present study, we were concerned to make minimal demands on subjects, since attrition rate in menstrual cycle research is high. Because our previous studies, with testing to extinction for up to $2 \mathrm{~h}$, had shown significant effects at only the first four tests with the highest significance levels at the first test, we required our subjects to make only a single adjustment match of initial strength (IS). For the reasons cited above, we expected the effects to decay completely between test days, although we did check for residual effects.

\section{Apparatus}

Three stimuli were used - two for adaptation, and one for testing. The adaptation stimuli consisted of black vertical or black horizontal square wave gratings ( $5 \mathrm{~mm}$ wide) drawn on white card, giving a spatial frequency of 1 cycle per degree. A green gelatine filter (color match Brilliant Green [28A8] on the Meuthen system) and a magenta gelatine filter (color match Bluish Red [1288] on the Meuthen system) were superimposed, one on the vertical and one on the horizontal grating. The corresponding CIE $x, y$ specifications are 
$0.292,0.462$ and $0.461,0.271$, respectively. The test card was divided vertically into two halves, each containing one of the black and white gratings.

The stimuli were presented in an Electronic Developments sixfield tachistoscope to induce monocular aftereffects, to control the illumination of the nonadapted eye and the timing of alternations during adaptation, and to regulate eye movements. The fields were matched for brightness by the minimal flicker method. Stimulus size was $16^{\circ}$ horizontally and $10^{\circ}$ vertically at the viewing distance of $56 \mathrm{~cm}$. Spot meter brightness measurements gave values of 9.6 and $6.2 \mathrm{~cd} / \mathrm{m}^{2}$ for the magenta and black and 4.1 and $2.3 \mathrm{~cd} / \mathrm{m}^{2}$ for the green and black.

The apparatus to match the magenta phantom color consisted of a birefringent 1.5 wave plate for green light, made from adhesive tape stretched across a glass slide and positioned between two parallel polarizing filters, viewed against white card illuminated by a Northern Daylight tube. When the angle $(C)$, between the slow direction of the plate and the transmission axis of the polarizers is at $0^{\circ}$, white light is transmitted. As the value of $C$ increases, a stronger magenta color is produced as more of the green wavelengths are subtracted. The strongest magenta color is produced when $C=45^{\circ}$. Spot meter readings gave values of approximately $45 \mathrm{~cd} / \mathrm{m}^{2}$ at $0^{\circ}$ and $15 \mathrm{~cd} / \mathrm{m}^{2}$ at $45^{\circ}$. $C$ is manipulated to correspond to the phantom color on the test stimulus and the value of angle $C$ is used to calculate ME strength as the percentage of green light retarded:

$$
\operatorname{ME}(\%)=100 \sin ^{2} 2 C \text {. }
$$

A similar apparatus was constructed to match the green component of the ME. Green, however, cannot be matched by simple destructive interference, although we were able to obtain a good match, expressed as $C$ degrees, using a 2 wave filter for red light. For this reason only the magenta data are presented in full, although in all these experiments, the green component was measured and analyzed.

\section{Subjects}

All subjects had normal or corrected vision and were screened for color vision anomalies. The subjects were all requested to abstain from caffeine, nicotine, and alcohol from the previous day. The subjects were also tested at approximately the same time of day at each test session.

All subjects completed a pretest in which they were familiarized with the apparatus, menstrual history was taken, and the date of their last period was established. The subjects were then assigned to starting phases, based on the assumption that the period between ovulation and menses is approximately 14 days (Asso, 1983). Each subject was tested once in each of the five phases of the menstrual cycle. The phase in which initial testing took place was counterbalanced across subjects to reduce the possibility of practice or cumulative effects. The date of the first period after testing was obtained later, to check that phase assignation had been accurate. Only 1 subject had to be retested because of a late period.

Although phase assignation through counting days has many limitations (Asso, 1983), hormonal assays were not attempted in this study because information about hormone concentrations in the periphery tells us very little about their concentrations in the CNS (Broverman, Klaiber, \& Vogel, 1980).

\section{Procedure}

As a control for spectral shift and cumulative and residual effects, subjects were shown the achromatic test gratings before adaptation and were asked to report what colors, if any, were apparent on the gratings. None were reported. To control for threshold shift, subjects were then asked to set the match-interference apparatus to "minimum magenta" using both ascending and descending adjustments. The difference between these adjustments provided a measure of anticipatory (positive) or perseverant (negative) response bias, and their average was used to make a pseudo-PSE correction.
Adapting stimuli, pairing color and pattern, were then presented for $7 \mathrm{~min}$; they alternated every $5 \mathrm{sec}$. Orientation-color contingencies were reversed between sessions. After a rest of $7 \mathrm{~min}$ following adaptation, to ensure the decay of afterimages, the test stimuli were presented to the adapted eye for $5 \mathrm{sec}$. The observer then looked away from the tachistoscope and matched the magenta and then the green component of the ME with the match-interference apparatus. The adjustment took about $5 \mathrm{sec}$.

Since our version of the match-interference method requires that subjects remember the phantom color for a few seconds while making the match, it is conceivable that changes in color memory could affect the reporting of the ME. To control for this possibility, a test of color memory was made at each test session. The subjects were shown a colored chip from the magenta or green ranges of the FarnworthMunsell 100 Hue test for $10 \mathrm{sec}$. After a further $10 \mathrm{sec}$, they were required to match that chip from memory in an array of similarly colored chips. Five matches were made.

\section{EXPERIMENT 1 The ME at Five Phases}

\section{Method}

Thirty-two women completed this experiment, 22 naturally cycling $(\mathrm{NC})$ women and 10 oral contraceptive (OC) users. They ranged in age from 18 to 41 years. All were classified as ambivert on the Eysenck Personality Inventory (EPI). Seven women in the OC group used Femodene, 1 used Mycrogynon 30, 1 Mercilon, and 1 Marvelon; all are combined pills, containing both estrogen and progesterone.

\section{Results}

Figure 1 shows a significant phase effect for magenta initial strength for the $\mathrm{NC}$ women, who reported increasingly stronger MEs across the cycle from the menstrual phase, culminating in a premenstrual peak. Oral contraceptive users, who reported significantly weaker MEs than did the NC women, showed no such phase effect.

The results for the magenta component of the ME were analyzed in a $2 \times 5$ mixed design analysis of variance (ANOVA). There was a highly significant interaction between menstrual cycle phase and subject group $[F(4,120)=$

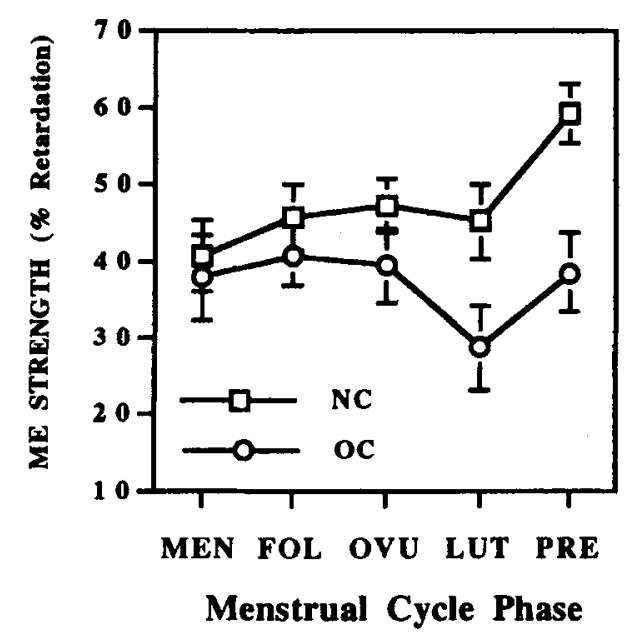

Figure 1. McCollough effect magenta initial strength ( $M$ and $S E$ ) at five phases of the menstrual cycle for 22 normally cycling (NC) women and 10 women using oral contraception (OC). 
$3.122, p=.0175]$. The main effect of phase was significant $[F(4,120)=3.146, p=.0169]$ but not that of group $[F(1,30)=2.920, p=.09]$. Simple effects analysis revealed that menstrual phase was significant for the $\mathrm{NC}$ women only $[F(4,120)=7.879, p<.0005]$, and not for the OC women $[F(4,120)=0.978, p=.422]$. NC women reported stronger MEs than did their OC counterparts at all tests, and these were significantly stronger in the premenstrual phase $[F(1,30)=10.993, p=.002]$.

When the data were subjected to the pseudo-PSE correction, by subtracting the mean minimum magenta settings from initial strength, the menstrual cycle phase $X$ group interaction survived the correction with increased significance $[F(4,120)=3.977, p=.0046]$, as did the simple effect for the NC group $[F(4,120)=5.398, p<.0005]$. The groups were significantly different at the luteal $[F(1,30)=5.001, p=.033]$ and premenstrual $[F(1,30)=$ $9.899, p=.004]$ phases. We found no significant order effect $[F(4,120)=0.403, p=.8]$ or interaction with group $[F(1,120)=1.50, p=.207]$ when the data were reanalyzed by order of test day rather than phase.

There were no significant effects in response bias, minimum magenta settings, or color memory. We also measured, using 40-trial staircase methods, critical flicker fusion thresholds (CFFT) as an indicator of cortical activation (Smith \& Misiak, 1976), and a concentric circles figural aftereffect (FAE) as an indicator of more peripheral neural adaptation. Neither effect varied with menstrual cycle phase.

According to our alternative predictions, the postovulatory increase in initial strength suggests that the ME was covarying with arousal rather than cholinergic activity. The hypothetical changes in arousal did not affect CFFT, however, which did not show the premenstrual peak observed by Dye (1992).

\section{EXPERIMENT 2 Phase Effect in Three CAEs}

Experiment 2 was designed to replicate the phase effect with a different subject group and to extend the observations to other contingent aftereffects. Dodwell and Humphrey's (1990) error correcting device model predicts that color aftereffects contingent on primitive Lie orbits, like the $\mathrm{ME}$, will be generated more easily, and be reported as more saturated than those contingent on other pattern pairs. We therefore chose, in addition to ME stimuli, a second primitive Lie orbit pair (radial lines and concentric circles) (RC) and a pair of high and low spatial frequency gratings (SF), which do not belong to the Lie group. Humphrey, Dodwell, and Emerson (1989) showed that the $\mathrm{ME}$ and the RC can exist independently and with no interference in a single observer. Since we had confirmed their observation, though with some reduction in ME strength (Maguire, 1996), we elected to induce and measure all three CAEs in each test session. Because flicker fusion thresholds had shown no change across the menstrual cycle in Experiment 1, we included instead a visual analogue rating scale (VARS) measure of arousal (e.g., Thayer, 1985).

\section{Method}

Subjects. A total of 20 women started the experiment, but only 9 $\mathrm{NC}$ women, between the ages of 18 and 36, completed it.

\section{Additional Stimuli}

Stimuli were drawn on white card and paired with the magenta and green filters as described in the General Method.

The RC stimuli consisted of black concentric circles and black "spokes" (radius $4.5 \mathrm{~cm}$ ) radiating from a single point. The test card was a black and white circle divided into four quadrants, two opposite quadrants contained part of the concentric circles pattern and two consisted of the radial lines pattern.

The SF stimuli were two horizontal gratings with spatial frequencies of 0.5 and 2.5 cycles/deg, respectively. They were high-quality black and white matte photographs taken from a Silicone Graphics Indigo screen and pasted onto card. The test card was divided into two halves, each containing one of the grating patterns.

\section{Procedure}

At the beginning of each session, the subjects completed the VARS and were then adapted to each of the three inducing stimulus pairs for $8 \mathrm{~min}$ in turn with a 2 -min rest between each adaptation period. Minimum magenta settings, response bias, and color memory were measured as before. Order of exposure to patterns was counterbalanced across trials and subjects. Five minutes after exposure to the last pattern pair, subjects were shown the test card that corresponded to the first pattern-color pair. Any reported aftereffects were measured with the match-interference method. The matching procedure was then repeated for the other two test stimuli in order of adaptation, with a 2 -min rest between tests.

\section{Results}

The data shown in Figure 2 have a pattern similar to that observed in Experiment 1 for ME and RC stimuli, with infrequent and much weaker effects reported for the SF stimuli. The mean aftereffect strength in $\mathrm{ME}$ and $\mathrm{RC}$, but not in SF, was significantly higher after ovulation, particularly in the premenstrual phase.

An ANOVA showed a significant interaction between stimulus pattern and cycle phase $[F(8,64)=3.747, p=$

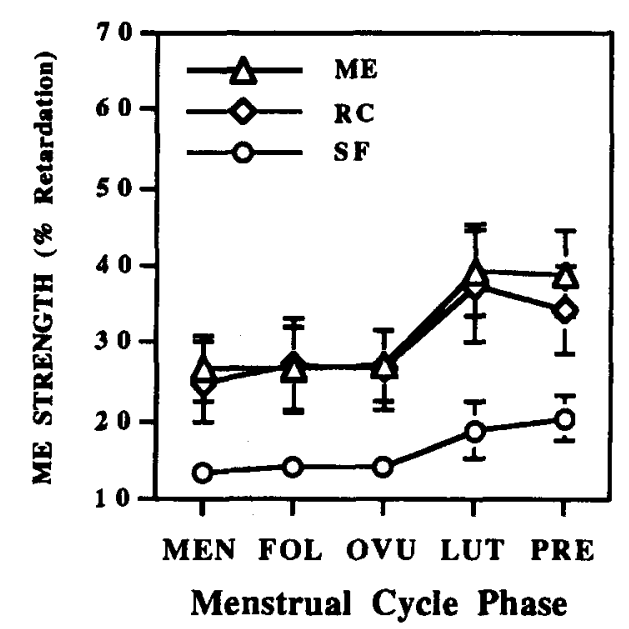

Figure 2. Pattern contingent color aftereffect magenta initial strength ( $M$ and $S E$ ) for McCollough (ME), radial lines/concentric circles (RC), and high/low spatial frequency (SF) stimuli at five phases of the menstrual cycle for 9 naturally cycling women. 
$.0012]$, with significant main effects of phase $[F(4,32)=$ $9.223, p<.0001]$ and stimulus pattern $[F(2,16)=11.719$, $p=.0007]$. Control measures did not vary over the menstrual cycle, and the effects survived the pseudo-PSE correction for the interaction $[F(8,64)=61.163, p=.0006]$, the stimulus effect $[F(2,16)=12.053, p=.0006]$, and the phase effect $[F(4,32)=80.016, p<.0001]$. The green component was reported by all subjects with the ME and RC stimuli, but showed no significant effects of phase or group. The green $\mathrm{ME}$ was consistently reported by all subjects as being less saturated than the magenta, so there was considerably less variation in the reports.

These findings offer some support for Dodwell and Humphrey's (1990) predictions, to the extent that the effects were much weaker in the SF condition. However, the ME magenta initial strengths were weaker than those reported in Experiment 1, which may indicate some interference between the horizontal components of the ME and $\mathrm{SF}$, although counterbalancing makes it impossible to verify this. Alternatively, the very weak SF effects may be attributable to the absence of the edge components described by Broerse and O'Shea (1995). None of the VARS measures showed any phasic effect, suggesting that no large changes in arousal were involved.

\section{DISCUSSION}

We have shown that the initial strength of the ME varies across the menstrual cycle. Our control measures indicate that these effects of cycle phase were independent of any changes in response bias, minimum magenta settings, or color memory, none of which varied significantly across the cycle. Experiment 1 demonstrated a significant premenstrual peak in the magenta component of the ME, and in Experiment 2 this finding was confirmed and extended to another pattern-contingent color aftereffect.

In the beginning of this paper, we offered two competing predictions of the way in which the ME might vary across the menstrual cycle. Since we had previously shown that the ME is sensitive to cholinergic activity (Byth et al., 1992), we suggested that the ME would be strongest in the first part of the cycle when rising estrogen levels reduce cholinergic activity. Alternatively, if the ME should be affected inversely by CNS arousal, ME strength would be greatest in the second part of the cycle when rising progesterone levels have a deactivating effect, reducing arousal.

Our data show a near linear increase in ME, with the strongest IS reported in the premenstrual phase. Levels of estrogen and progesterone remain relatively high for the early part of this phase before falling sharply at around Day 27 or 28 of the standardized cycle. The postovulatory combination of estrogen and progesterone has a deactivating effect on the CNS, reducing arousal. This suggests that the ME varies inversely with reduced arousal in the later part of the cycle. Although this interpretation is tempting, we found no associated changes in CFFT or VARS, which we might expect to vary with arousal. How- ever, we have found that the ME is a more sensitive indicator of therapeutic drug doses than most standard psychomotor tests (Byth et al., 1992), and we do not wish to rule out an arousal explanation.

We found that $\mathrm{OC}$ users have reduced MEs relative to NC women, except at the menses. This was unexpected, since $\mathrm{NC}$ women report strongest MEs when progesterone levels are high and OC users have progesterone present for their entire cycle, except during the 7 pill-free days that cause the "withdrawal bleed." OC users show a cyclical pattern similar, though nonsignificant, to that of the NC women, with the exception of a nonsignificant luteal dip for OC users. Perhaps the oral contraceptives are masking or dampening a circacirtaginian rhythm that is also responsible for the menstrual cycle. Findings in olfaction suggest similar patterns of response in both NC and OC women, with the responses of the latter reduced (Doty et al., 1981).

Attempting to explain the pattern of contingent aftereffect initial strength across the menstrual cycle purely in terms of estrogen- and progesterone-mediated changes in arousal and cholinergic activity is admittedly overly reductionist. Many other hormones are involved in the menstrual cycle, such as, for example, gonadotrophin releasing hormone (GnRH), FSH, $\mathrm{LH}$, and prolactin. It is by no means clear how these hormones affect arousal or how they may interact with estrogen and progesterone in terms of performance (Asso, 1983). It is equally unclear how neurotransmitters are affected by hormones (Broverman et al., 1980), and the implications of these interactions for arousal are also far from clear.

These experiments show that the ME and at least one other related aftereffect are sensitive to menstrual cycle phase. Our controls suggest that this finding cannot be attributed to cyclical fluctuations in color thresholds or color memory. It seems likely that the variability in ME strength is attributable to hormonally mediated changes in CNS arousal across the cycle.

\section{REFERENCES}

Allan, L. G., \& Siegel, S. (1986). McCollough effects as conditioned responses: A reply to Skowbo. Psychological Bulletin, 100, 388-393. AMURE, B. O. (1978). Nicotine and the decay of the McCollough effect. Journal of Physiology, 295, 32P.

ANDREWS, D. P. (1964). Error correcting perceptual mechanisms. Quarterly Journal of Experimental Psychology, 16, 104-115.

ANSTIS, S. M. (1975). What does visual perception tell us about visual coding? In M. S. Gazzinaga \& C. Blakemore (Eds.), Handbook of psychobiology (pp. 269-323). New York: Academic Press.

Asso, D. (1983). The real menstrual cycle. New York: Wiley.

BroERSE, J., \& O'SHEA, R. P. (1995). Local and global factors in spatiallycontingent coloured aftereffects. Vision Research, 35, 207-226.

Broverman, D. M., Klaiber, E. L., \& Vogel, W. (1980). Gonadal hormones and sensory functioning. In J. E. Parsons (Ed.), The psychobiology of sex differences and sex roles (pp. 59-80). New York: McGraw-Hill.

Broverman, D. M., Vogel, W., Klaiber, E. L., Majcher, D., Shea, D., \& PAUL, V. (1981). Changes in cognitive task performance across the menstrual cycle. Journal of Comparative \& Physiological Psychology, 95, 646-654. 
Byth, W., Logue, N. A., Bell, P., Best, S. J., \& KING, D. J. (1992). The McCollough effect as a measure of central neurotransmitter activity in man. Psychopharmacology, 106, 75-84.

BYTH, W., \& MAGUIRE, M. S. (1995). Studying the McCollough effect: Phantom colours and pharmacology. Irish Journal of Psychology, 16, 276-287.

DodWell, P. C., \& HumPhreY, G. K. (1990). A functional theory of the McCollough effect. Psychological Review, 97, 78-89.

DoDWELl, P. C., \& O'SHEA, R. P. (1987). Global factors generate the McCollough effect. Vision Research, 27, 569-580.

DotY, R. L., Huggins, G. R., SNYDER, P. J., \& LoWRY, L. D. (1981). Endocrine, cardiovascular and psychological correlates of olfactory sensitivity changes during the human menstrual cycle. Journal of Comparative \& Physiological Psychology, 95, 45-60.

DYE, L. (1992). Visual information processing and the menstrual cycle. In J. T. E. Richardson (Ed.), Cognition and the menstrual cycle (pp. 67-97). New York: Springer-Verlag.

EYSENCK, H. J. (1967). The biological basis of personality. Springfield, IL: C. C. Thomas.

GANDLEMAN, R. (1983). Gonadal hormones and sensory function. Neuroscience \& Behavioural Reviews, 7, 1-17.

HARRIS, C. S. (1980). Insight or out of sight? Two examples of perceptual plasticity in the human adult. In C. S. Harris (Ed.), Visual coding and adaptability (pp. 95-149). Hillsdale, NJ: Erlbaum.

HARRIS, J. P. (1987). Contingent perceptual aftereffect. In R. L. Gregory (Ed.), The Oxford companion to the mind (pp. 66-68). Oxford: Oxford University Press.

Humphrey, G. K., Dodwell, P. C., \& Emerson, V. F. (1985). The roles of pattern orthogonality and color contrast in the generation of patterncontingent color aftereffects. Penception \& Psychophysics, 38, 343-353.

Humphrey, G. K., Dodwell, P. C., \& Emerson, V. F. (1989). Patterncontingent color aftereffects on noninduced patterns. Perception \& Psychophysics, 45, 97-109.

Jones, P. D., \& Holding, D. H. (1975). Extremely long-term persistence of the McCollough effect. Journal of Experimental Psychology: Human Perception \& Performance, 1, 323-327.

KaUfMAN, J. H., MAY, J. G., \& KUNEN, S. (1981). Interocular transfer of orientation-contingent color aftereffects with external and internal adaptation. Perception \& Psychophysics, 30, 547-551.

LoGUE, N. A., \& BYTH, W. (1993). Extraversion and the McCollough effect. British Journal of Psychology, 84, 67-84.

MACKAY, D. M., \& MACKAY, V. (1974). The time course of the McCollough effect and its physiological implications. Journal of Physiology, 237, 38-39.

MAGUIRE, M., (1996). Pattern contingent colour aftereffects (PCCAEs) and the menstrual cycle. Unpublished doctoral dissertation, The Queen's University of Belfast.

MaguiRe, M., \& BYTH, W. (1995). Caffeine, menstrual cycle and the McCollough effect [Abstract]. Proceedings of the British Psychological Society, 3, 125.

MCCARTER, A., \& Silver, A. (1977). The McCollough effect: A classical conditioning phenomenon? Vision Research, 17, 317-319.

McCollough, C. (1965). Color adaptation of edge detectors in the visual system. Science, 149, 1115-1116.
McMAHON, D. (1993). The McCollough effect as an indicator of central neurotransmitter activity in man. Unpublished doctoral dissertation, The Queen's University of Belfast.

MikAELIAN, H. H. (1975). Interocular generalization of orientation specific color aftereffects. Vision Research, 15, 661-663.

MURCH, G. M. (1976). Classical conditioning of the McCollough effect: Temporal parameters. Vision Research, 16, 615-619.

MuRCH, G. M. (1977). A reply to McCartan and Silver. Vision Research, 17, 321-322.

PARLEE, M. B. (1983). Menstrual rhythm in sensory processes: A review of fluctuations in vision, olfaction, audition, taste, and touch. Psychological Bulletin, 93, 539-548.

RICHARDSON, J. T. E. (1992). Cognition across the menstrual cycle. In J. T. E. Richardson (Ed.), Cognition and the menstrual cycle (pp. 1-38). New York: Springer-Verlag.

Riggs, L. A., WhiTE, K. D., \& Eimas, P. D. (1974). Establishment and decay of orientation-contingent aftereffects of color. Perception \& Psychophysics, 16, 535-542.

SHUTE, C. C. D. (1977). A device for measuring the McCollough effect (ME) using polarised light. Journal of Physiology, 265, 2-3.

SHUTE, C. C. D. (1979). The McCollough effect. Cambridge: Cambridge University Press.

Sкошво, D. (1984). Are McCollough effects conditioned responses? Psychological Bulletin, 96, 215-226.

Sкошво, D. (1986). McCollough effects as conditioned responses? Reply to Allan and Siegel. Psychological Bulletin, 100, 394-397.

Skowbo, D., GarRITy, S., \& Michaud, L. (1985). Does testing initiate decay of McCollough effects? Perception \& Psychophysics, 37, 377-381.

Skowbo, D., Timney, B. N., Gentry, T. A., \& Morant, R. B. (1975). McCollough effects: Experimental findings and theoretical accounts. Psychological Bulletin, 82, 497-510.

Smith, J. M., \& MisiaK, H. (1976). Critical flicker fusion and psychotropic drugs in normal man-a review. Psychopharmacology, 47, 175-182.

SPEHLMANN, R., \& DownES, K. (1974). The effects of acetylcholine and of synaptic stimulation on the sensorimotor cortex of cats: 1 . Neuronal responses to stimulation of the reticular formation. Brain Research, 74, 229-242.

THAYER, R. E. (1985). Activation (arousal): The shift from a single to a multidimensional perspective. In J. Strelau, F. Farley, \& A. Gale (Eds.), The biological basis of personality and behaviour (Vol. 1, pp. 115-127). New York: McGraw Hill.

VIDYASAGAR, T. R. (1976). Orientation specific colour adaptation at a binocular site. Nature, 261, 39-40.

WHITE, K. D. (1977). Summation of successively established orientationcontingent color aftereffects. Perception \& Psychophysics, 22, 123-136.

White, K. D., Petry, H. M., Riggs, L. A., \& Miller, J. (1978). Binocular interactions during establishment of McCollough effects. Vision Research, 18, 1201-1215.

(Manuscript received May 30, 1996; revision accepted for publication January 31, 1997.) 